Why do they do (h)it? Using Self-Determination Theory to understand why people start and continue to do high intensity interval training (HIT) group exercise classes.

Naomi Burn ${ }^{1}$ and Ailsa Niven ${ }^{2}$

Health and Social Care Institute, Teeside University

Physical Activity and Health Research Centre, University of Edinburgh 


\section{Why do they do (h)it? Using Self-Determination Theory to understand why people start and continue to do high intensity interval training (HIT) group exercise classes.}

\section{Abstract}

Objective: High intensity interval training (HIT) has emerged in recent years as an alternative form of exercise for health improvement. However, due to the maximal or near maximal effort nature of HIT there have been questions regarding the appeal of HIT, and the likelihood that individuals will maintain involvement over time. Limited research has considered the motivational processes influencing participation in HIT. The objective of this qualitative study was to use Self-Determination Theory as a framework to understand the reasons why exercisers start and maintain their involvement in HIT group exercises classes, and how a HIT environment may support their motivation.

Methods: Semi-structured interviews were conducted with 12 purposively sampled participants (mean age $=22.75$ years) who had regularly attended HIT group exercise classes for $\geq 6$ months Interviews were digitally recorded, transcribed and data were thematically analysed incorporating inductive and deductive procedures.

Results: Participants started and continued HIT for a number of reasons that were mainly intrinsic and underpinned by behavioural regulations predominantly reflective of autonomous motivation. Participants identified a broader range of reasons for continuing HIT than starting HIT. The HIT structure, HIT exercises, instructors and other class attendees created an environment that supported autonomy, competence and relatedness.

Conclusion: Some individuals can be motivated to participate in HIT for reasons that are positively associated with adaptive behavioural, affective and cognitive outcomes. HIT classes can be designed to support needs satisfaction, and promote continued engagement. 


\section{Introduction}

The benefits of physical activity for physical and psychological health are well established (Lee et al., 2012). Current UK guidelines recommend that to achieve these health benefits adults should undertake 150 minutes of moderate to vigorous intensity physical activity, or 75 minutes of vigorous intensity physical activity (or a combination thereof) per week (Department of Health, 2011). However, many people do not achieve these levels and due to its global prevalence, inactivity has been labelled as 'pandemic' (Kohl et al., 2012). One of the most commonly cited barriers to physical activity (and exercise) participation is lack of time (Justine et al., 2013; Sequeira et al., 2011) which has prompted research interest into more time efficient forms of physical activity for health improvement.

High-intensity interval training (HIT) is characterised by brief, intermittent bursts of relativley vigorous intensity or all-out exercise, interspersed with periods of rest or low intensity exercise (Gibala, Little, Macdonald, \& Hawley, 2012). An array of HIT protocols have been utilised to date and a recent review identified protocols with total exercise time ranging from 40 seconds to 26 minutes (excluding recovery time) (Milanovic, Sporis, \& Weston, 2015). Although an optimal prescription of HIT to promote health and fitness outcomes has yet to be established, current work suggests HIT produces equal or superior improvements in cardiorespiratory fitness (Milanovic et al., 2015), and metabolic risk factors (Kessler, Sisson, \& Short, 2012) than longer periods of continuous moderate intensity exercise.

However there is debate surrounding the feasibility of HIT as a public health solution to promote the health related benefits of physical activity participation. Opponents of HIT have argued that the experience of HIT is unlikely to motivate individuals to regularly participate in HIT. Specifically, it has been suggested that HIT could lead to unpleasant affective responses, undermine feelings of competence, and be less enjoyable than less intense activity (Biddle \& Batterham, 2015; Hardcastle, Ray, Beale, \& Hagger, 2014). Proponents of HIT have countered these arguments 
(Biddle \& Batterham, 2015; Jung, Little, \& Batterham, 2016), drawing in part from the growing body of research examining affective respones to HIT (e.g., Jung, Bourne, \& Little, 2014); however the findings relating to affective responses to HIT are inconsistent between studies (Decker \& Ekkekakis, 2017).

Contrary to the arguments that HIT would have limited appeal, HIT appears to be popular as it has been consistently ranked in the top 3 of ACSM's survey of world fitness trends for the last three years (Thompson, 2014, 2015, 2016). This popularity suggests that some individuals might be willingly participating in this form of exercise, commonly in group exercise classes. However, limited research to date has considered why individuals choose to start and continue to participate in this form of exercise. An exception is Thogersen-Ntoumani, Shepherd, Ntoumanis, Wagenmakers, and Shaw (2016) who examined the correlation between motivational variables and adherence during a 10 week class-based cycling HIT intervention. The authors concluded that intrinsic motivation was a positive predictor of adherence to the HIT programme. Whilst a useful study, there is a need to further understand the motivational processes underpinning participation in HIT, particularly in nonintervention, free living participants in order to inform the debate around the implications of HIT for public health. Furthermore, in their recent scoping review of psychological responses to interval exercise protocols Stork and colleagues (Stork, Banfield, Gibala, \& Martin Ginis, 2017) did not identify any papers utilising qualitative methods, and highlighted the need for qualitative research in order to provide a richer insight into the factors associated with motivation for HIT over time.

\section{Self Determination Theory}

Self-determination theory (SDT) is a theoretical framework of personality, motivation and wellbeing that has been used extensively to understand and promote physical activity behaviour (Teixeira, Carraca, Markland, Silva, \& Ryan, 2012). The current iteration of SDT is composed of 6 mini-theories (Ryan \& Deci, 2017) (and concepts from Goal Content Theory (GCT), Organismic Integration Theory (OIT) and Basic Psychological Needs Theory (BPNT) have received the most 
attention in physical activity research (Teixeira et al., 2012). In this study, we draw on these mini theories to provide a framework to increase understanding of why people participate in HIT over a period of time. Goal content theory (GCT) (Deci \& Ryan, 2000) provides a useful perspective for examining what individuals are aiming to achieve by engaging in HIT. With some similarities to exercise participation motives (Ingledew \& Markland, 2008), within GCT exercise goals are differentiated into intrinsic and extrinsic goals according to the focus of the goal. Intrinsic goals are internally focused (e.g., enjoyment, social affiliation), whereas extrinsic goals have a more external focus (e.g., appearance, social recognition) (Sebire, Standage, \& Vansteenkiste, 2009). Compared with extrinsic exercise goals, intrinsic goals are positively associated with exercise behaviour (Teixeira et al., 2012), and adaptive cognitive and affective outcomes (Sebire et al., 2009).

In addition to understanding the 'what' of goal pursuits, OIT provides a framework for also understanding the 'why' (Deci \& Ryan, 2000), which helps to address the difficulty in categorising some motives as exclusively intrinsic or extrinsic (Markland \& Ingledew, 1997; Sebire et al., 2009). Specifically, behavioural regulations underpin the intrinsic and extrinsic goals, and are positioned on an autonomy continuum depending on the extent to which they are controlled by external factors, and integrated into the individual's sense of self (R. M. Ryan \& Deci, 2000; Standage \& Ryan, 2012). The continuum includes intrinsic regulation, which underpins intrinsic motivation when an individual does an activity for its own inherent satisfaction. Four sub-types of behavioural regulation underpin extrinsic motivation. External regulation is the most controlled type of extrinsic motivation and relates to actions undertaken to obtain external rewards or avoid punishment. Introjected regulations relate to actions undertaken to obtain or avoid self-imposed feelings of guilt or enhance self-worth. More autonomous behavioural regulations include identified regulation, where the action is personally valued, and integrated regulation where the individual identifies with the action and it is congruent with their sense of self. These behavioural regulations are commonly subdivided into controlled behavioural regulations, incorporating external and introjected, and autonomous behavioural regulations incorporating intrinsic, identified, and integrated regulations. 
Compared with controlled, autonomous behavioural regulations are consistently positively associated with physical activity (Teixeira et al., 2012), and other positive outcomes such as more positive attitude towards physical activity (Vierling, Standage, \& Treasure, 2007), and stronger intentions to be active (Rouse, Ntoumanis, Duda, Jolly, \& Williams, 2011). If individuals start and maintain a form of exercise such as HIT over a period of time, then it is probable that autonomous behavioural regulations are underpinning the motives for participation and influencing the behaviour.

A strength of SDT is that it identifies the conditions that will support more autonomous motivation. Specifically, SDT posits that all humans have three innate basic psychological needs (BPNs) of autonomy, competence, and relatedness (Deci \& Ryan, 2000). Autonomy involves feelings of willingness and self-endorsement for the behaviour; competence involves feeling able to undertake the behaviour or master challenges; and relatedness refers to feelings of closeness or being cared for by others. Social environments that are supportive of these needs can facilitate autonomous motivation (Deci \& Ryan, 2000), leading to more enduring behaviour. Exercise-related research provides some support for this proposition with competence showing a stronger and more consistent relationship with autonomous motivation (Wilson \& Rogers, 2008) and exercise behaviour (Teixiera et al., 2012) than autonomy and relatedness. Nevertheless, understanding participants' perceptions of the HIT social environment will help identify if and how classes can support BPNs, and potentially facilitate the development of autonomous motivation.

To summarise, although there is considerable debate about the appeal of HIT in the general population, it has grown in popularity within the commercial exercise sector and is linked with improvements in health and fitness outcomes (e.g., Kessler et al., 2012; Milanovic et al., 2015). However, limited theoretically based research (e.g., Thogersen-Ntoumani et al., 2016) has considered what motivates those individuals who do participate in HIT on a regular basis, despite such research having the potential to contribute to the ongoing debate (Stork et al., 2017). Therefore, the overall aim of this study was to draw on SDT to understand the motivational 
processes influencing participants starting and continuing to participate in HIT group exercise classes. Two specific research questions were addressed:

(1) what are the goals and underpinning behavioural regulations of individuals who have been participating in HIT classes for $\geq 6$ months when they started and continued participating

(2) what elements of a HIT class help to create a needs supportive environment for participants?

\section{Method}

The reporting of this study adheres to the consolidated criteria for reporting qualitative research (COREQ) (Tong, Sainsbury, \& Craig, 2007). The COREQ checklist is presented in Supplementary file 1.

\section{Participants and Recruitment}

Twelve adult participants ( 1 male) aged $19-26$ years (mean $=22.75)$ were purposively sampled because they had been attending HIT group exercise classes regularly (usually at least once per week) for more than 6 months at a university gym in Edinburgh, Scotland. Four participants were undergraduate students, six were post graduate students and two were university educated professionals. HIT group exercise classes were defined as any group exercise class offered at the gym that was structured to involve brief periods of vigorous intensity aerobic exercise interspersed with rest periods or low intensity exercise for the duration of the class. The classes attended by participants were Insanity ${ }^{\mathrm{TM}}$, Metafit $^{\mathrm{TM}}$ and Tabata $^{\mathrm{TM}}$. These classes are between 30 to 50 minutes in duration and include a range of high impact body weight exercises (e.g. burpies, high knee runs, squat jumps). High intensity sets last between 20 -seconds to 3 -minutes, with between 10 -second to 1-minute rest periods. All participants retrospectively completed the Borg RPE scale (Borg, 1970) based on their regular class and the average score was $16.75(S D=1.21)$, between hard and very hard. This score is classified by Borg as 'high intensity'. The participants' average length of class attendance was 13 months (range 6-24 months). 
Following guidance on reporting of qualitative research, brief details relating to the researchers are also given to provide insight into the perspectives they bring to the research (Tong et al., 2007). The lead researcher was a female postgraduate student with lived experience of HIT classes. The lead researcher had 1 year of previous qualitative research methods experience, and had received appropriate training in qualitative research methods. The lead researcher conducted all interviews and data analysis. The second researcher was an academic experienced in working with qualitative research methods in sport and exercise psychology, and also had lived experience of HIT classes. The second researcher coded a subset of transcripts and conducted peer debriefing during theme development.

\section{Instrument}

The interviews focused on physical activity history, exploration of motivation for beginning and continuing HIT classes (e.g., what were the reasons for you starting/continuing HIT?), and exploration of elements of a HIT class that could create a needs supportive environment (e.g., tell me about the instructors of the class?). The interview schedule was piloted on one participant before the schedule was finalised, and minimal changes were made (e.g. the order of the questions were rearranged to improve the flow of the interview).

\section{Procedure}

Following institutional ethical approval, participants from 10 HIT classes who met the inclusion criteria (i.e., regular participants for $>6$ months) were invited to take part in the study. The lead researcher attended the beginning of HIT classes to introduce the research project, and gave business cards to interested attendees. Interested participants $(n=16)$ contacted the researcher and were sent full information about the study. Twelve participants consented to take part in the study and participated in a one-to-one interview on the university campus (lasting between 22-45 minutes). In qualitative research it is recommended that data collection continue 
until data saturation is reached which is defined as "the point in data collection and analysis when new information produces little or no change to the codebook" (Guest, Bunce \& Johnson, 2006, pg 65). Following the final interview, it was apparent that no new themes were emerging so a judgement was made that saturation had been reached and no additional participants were recruited. All interviews were audio-recorded and transcribed verbatim after each interview.

\section{Analysis}

An inductive-deductive approach to thematic analysis was utilised following Braun and Clarke (2006) six steps to thematic analysis using NVivo 10. The first step of familiarisation with the data included both verbatim transcription and re-reading the transcripts by the lead researcher. Secondly, transcripts were read line-by-line to generate initial codes. In order to assess the consistency and clarity of coding both researchers coded one transcript, and the lead researcher recoded three additional transcripts twice. The researchers discussed the coding process and rationale for the decisions providing confidence in the procedure. Codes were then deductively organised based on the concepts of SDT into goal contents and BPNT. The third step of searching for themes was conducted within these broad groupings, and codes were inductively clustered with similar codes into candidate themes. In some instances, codes were related to two themes and were therefore clustered under both (e.g., enjoy a challenge was clustered under enjoyment and challenge). In the fourth step, the lead researcher conducted an iterative process of reviewing and refining the themes to ensure coherence within and differences between the themes. At this point, the behavioural regulations underpinning the goal contents were identified by interpreting the context in which the participants spoke about the individual goal contents. The lead researcher then presented the thematic map to the second researcher who asked the researcher to justify the rationale, rigour and consistency of the analysis. In the fifth step, the researchers participated in an iterative process of defining and naming each theme, and at this point the goal content names were 
refined to align with Markland and Ingledew (1997). In the sixth step, the researchers presented the themes in a coherent and logical way with illustrative quotes (Braun \& Clarke, 2006).

\section{Results}

All participants discussed high levels of physical activity before beginning HIT classes. Some were involved in sporting teams ( $n=9)$, all had previously attended a gym, and most had attended other forms of group exercise class before beginning HIT classes.

\section{Goal contents and Behavioural Regulations}

Starting HIT classes

Figure 1 illustrates the four themes that emerged relating to participants' goals for starting HIT classes and the behavioural regulations interpreted as underpinning these goals. The theme 'Strength and Endurance' related to participants aiming to enhance these aspects of fitness through participation in HIT, and was the most commonly discussed goal. Some participants reported using HIT as a means to increase or maintain strength or endurance for sport. For example, Participant 5 stated "I was looking for something high intensity to improve my general fitness and improve my endurance particularly. Which was something I felt was holding me back a bit at the time [in sport]." For Participant 5, she was motivated to do HIT to improve her strength and endurance because she valued this benefit for her sporting goals, suggesting that identified behavioural regulation was underpinning her behaviour. Social affiliation goals emerged as a theme from participants' comments that a friend had recommended HIT or encouraged them to attend class with them. Participant 7 indicated that social affiliation was experienced as external regulation by discussing that "I think um my friends went to that [class] and they made me ((laughs)), they made me try it. And at first, I was quite anxious [because] I'm not very good at cardio. And then I really enjoyed it". Whereas for others, social affiliation goals were related more to intrinsic behavioural regulations because they enjoyed time with friends. 
The theme Stress Management emerged from participants' comments that HIT provided them with a break from work or studies. For example, Participant 3 discussed that:

I think it was something to take my mind off... [because] I'm on quite an intense course it was quite like to take my mind away from the course while in the most anti-social way possible not having other people I know talk to me or be in the class. So I was able to fully concentrate on the exercise.

Similar to the strength and endurance theme, it may be suggested that this goal was underpinned by identified behavioural regulation because participants valued that HIT took their mind off work or studies. The theme 'Appearance' was not explicitly mentioned as a reason for participation. Nevertheless, two participants commented that HIT could influence their appearance suggesting that it may be influential on why they do HIT. For example Participant 7 stated although her main goal for starting HIT was to get fitter, appearance may have been an additional consideration "I guess [to get] fitter. Yeah I mean maybe the way my body looks would be a nice byproduct but I guess fitter". This finding can be interpreted in two ways; firstly, if the participants felt societal pressure to maintain a certain body shape then it could suggest that for these participants introjected behavioural regulation partially underpinned the behaviour. Alternatively, if these participants personally valued this certain body shape then this would indicate identified regulation as influencing behaviour.

Finally, the theme 'Dissatisfied with Current Routine' emerged from many participants discussing that although they were currently physically active, they were either bored or looking to try something new when they began HIT. For example, Participant 2 reported:

I had done circuits for many years and I was starting to get bored of it. And I knew this was something slightly different but also equally as intense. And I had seen it on sort of social websites probably social media. I had seen it was something to do. 
Although this was not discussed as a "goal" for starting HIT, it was discussed by many participants as a reason they chose to first attend a HIT class.

Continuing HIT classes

Figure 2 illustrates the seven themes that emerged relating to participants' goals for continuing HIT classes, and the underpinning behavioural regulations. The themes of Strength and Endurance, Social Affiliation, and Appearance were evident as reasons for both starting and continuing HIT. In relation to Strength and Endurance, Participant 5 noted that she valued activities that improve her sports performance:

I suppose it is slightly addictive in a sense. I suppose you start doing things and then feel good that you are getting stronger and stuff so you keep doing it. Um mostly it's because I play a sport that I really really enjoy and it gives me the drive to do lots of other things to keep getting better at that.

Additionally when participants noticed improvements in either their general, or sport specific strength and endurance this reinforced their goal. For example, Participant 10 discussed that "my goal for this year was to like really improve my stamina. And like HIT really does help you do that", these examples may demonstrate identified regulation.

Social Affiliation was important for participants who perceived HIT classes as time to spend with friends. Some participants experienced social affiliation as externally regulated because they felt "peer pressure" to attend a HIT class. Participant 10 demonstrated this by discussing that "well my friends kept going so it was a little bit of peer pressure ((laughs)). And also I wanted to prove to myself that next time I'm not going to get as tired as I got the first time". Whereas others found social affiliation to be intrinsically motivating because they discussed enjoying "...spending some nice time with my friends" (Participant 7). Similarly to goals for starting HIT, although appearance was not explicitly discussed as a goal for continued HIT participation, it was discussed by the same two 
participants that they perceived HIT was beneficial because it could "tone" the body. As considered above, a focus on appearance-related goals could be underpinned by either introjected or identified regulations.

The themes of Challenge, Revitalisation, Enjoyment and Positive Health were new themes that were only related to continued HIT participation. Challenge emerged as a theme because it reflected participant's comments that they were motivated by the challenging nature of HIT. Further, accomplishing the challenge of HIT engendered feelings of pride and participants enjoyed mastering a challenge and noticing performance improvements. Participant 7 demonstrated this by stating that "and I started to enjoy challenging myself as well". These findings indicate that for participants the goal of challenge was underpinned by intrinsic behavioural regulation.

Revitalisation emerged as a theme from participants highlighting that they were motivated to participate by how they would feel after the class. For example, Participant 6 described the feeling after a HIT class:

I'm usually very happy to have a lie down and a stretch. But I feel pretty satisfied. Especially all the HIT sort of workouts that I do, I try and do them in the mornings. So I quite like the way it sort of sets me up for the day. It does make me feel refreshed and quite satisfied with the workout that I've just done. Yeah... I don't know... [I feel] relatively positive after a HIT class.

Revitalisation was experienced as intrinsic motivation because participants enjoyed how they felt after a HIT class. Revitalisation was also experienced as identified regulation because participants discussed that feeling revitalised allowed them to be more productive in other areas of their lives that they valued, such as work or study. 
Importantly participants discussed enjoyment frequently as a reason for continued HIT engagement. Participant 2 discussed that "I do really really enjoy it" demonstrating underlying intrinsic behavioural regulations. Additionally, Participant 3 described this feeling:

I get quite excited because I'm like 'yes I'm getting to do something that's not work' and I'm getting to actually... yeah as I say I enjoy the classes. So sort of like I do look forward to going to it.

Interestingly some participants mentioned that their enjoyment for HIT took time to develop: "I've been going every Friday and it was a kind of learn to love it thing for me." Lastly, positive health was noted as a motive by Participant 10 who said:

I can see that if I do go every week I am actually getting healthier and healthier. I can like... I don't die and I don't get out of breathe and stuff. So it does work for my health.

This participant valued that HIT made her feel healthier, indicating identified regulation.

\section{Creating a Needs Supportive Environment}

Figure 3 illustrates the four themes relating to the need supporting nature of the HIT social environment. A theme labelled 'HIT Structure' was identified from participants' comments that the work-rest cycle structure of HIT supported their competence in the activity. For example, Participant 3 discussed that the frequent short rest breaks permitted recovery: "It gives you time to recover without having too much time or too little". This recovery time allowed participants to feel capable of completing the exercises to the best of their ability as demonstrated by Participant 7: "But at the same time after completing every round I was like 'ok, I've done it'. So I can still do it". Some participants reported that knowing about the intermittent nature of the class was important to help support their feelings of competence that they could sustain the high intensity exercise throughout the class. For example, Participant 5 discussed using the structure in particular for self-talk during the class: "I suppose because of the intervals, trying to take it a little bit at a time. Saying "we're 
almost at the end of this bit" and "I can keep going" for this other last 10 seconds or whatever it is". This self-talk helped this participant feel capable of completing the class. However, other participants discussed that being oblivious to the structure of the class might encourage them to be "present" or "in the moment" which might help them to enjoy the feeling of the exercise itself, thus promoting competence.

A theme labelled 'HIT Exercises' emerged from participants' comments relating to the specific exercises that made up the class. Firstly, participants discussed that having a variety of different exercises within a class supported feelings of competence because there would be some exercises they were able to do. For example, Participant 9 reported "Even if maybe 3 or 4 exercises are like really tiring, there's always some definitely that you are gonna prefer". Additionally, participants reported that for each exercise the instructor would offer a challenging main exercise and a modified less challenging exercise. The impact of the modified exercises was discussed by Participant 3:

You can do the harder one for one round and then you can be like 'I can't keep that up' and take it back. Equally the other way, it's nice to be able to see that there is somewhere to go [...] say for the next class, next time there is somewhere for me to improve.

It was apparent that the inclusion of modified exercises supported both autonomy by allowing participants to choose their own level of intensity, and competence because the participants felt that the exercises could be tailored to their fitness level, and that they could improve over time.

The theme 'Instructor' emerged from comments relating to how the participants perceived the instructors. Firstly, the participants perceived that the communication style that the instructors used was very important. When the instructors used a communication style that supported the participants to choose the modified exercises when necessary, participants felt able to choose their own level of intensity, which provided autonomy support and enhanced their feelings of 
competence that they could complete the whole class. Participant 4 discussed that competence was supported by instructors who were encouraging throughout the class by saying that "... you feel kind of safe but also like motivated by her like fire and power that she's got when she's like saying stuff" . Additionally, Participant 8 discussed that it was important that instructors ensured participants were exercising correctly, demonstrating this could support competence: "I'd rather they said that [I was doing something incorrectly], than had me doing it all wrong [...] so I'm not embarrassed by it". The instructors could support relatedness if participants perceived they cared about members of the class and if they supported a cohesive group dynamic with statements like "let's do this together". Lastly, the participants viewed the instructors as "normal people" which promoted competence as discussed by Participant 4 "They're just normal people [...] and you're like [...] well if they're doing it, then I can do it".

A theme labelled 'Other Class Participants' emerged from comments relating to coexercisers. Many participants reported that it was important to have a friend to attend the first HIT class. However, views on the importance of attending class with friends after $\geq 6$ months were inconsistent. Some participants found attending class with a friend was still important, whereas others specifically chose to go to class alone. Regardless of this, participants felt related to other people in the class because they were "all in the same boat". Additionally, Participant 12 discussed that the group exercise environment helped to sustain high intensity exercise throughout the class, and therefore supported competence "I like the group fitness [...] atmosphere [...] being in an atmosphere that makes me really push through the whole thing, that sort of kept me going".

\section{Discussion}

Despite the growing popularity of HIT (Thompson, 2016) and research interest into the health and fitness outcomes associated with HIT (Kessler et al., 2012; Milanovic et al., 2015) limited work to date has considered why individuals may choose to start and continue to participate in this form of exercise. The aim of this study was to use SDT to explore the motivational processes 
influencing participation in HIT exercise classes by examining the reasons why some participants start and continue to do HIT, and how HIT classes can be motivational.

\section{Goal contents and Behavioural Regulation}

It was evident that individuals participated in HIT for a number of reasons. Participants started HIT with goals related to strength and endurance, social affiliation, appearance and stress management. Whilst these goals were also pertinent for individuals' continued participation in HIT, participants also reported that they were motivated to continue by challenge, enjoyment, revitalisation and positive health. The majority of these goals for both starting and continuing to participate in HIT are viewed as intrinsic (Ingledew \& Markland, 2008; Sebire et al., 2009), and the behavioural regulations underpinning these motives were predominantly reflective of autonomous motivation. These findings are encouraging because it shows that some individuals can be motivated to start and continue to participate in HIT for reasons that are positively associated with physical activity behaviour generally (Teixeira et al., 2012), HIT specifically (Thogersen-Ntoumani et al., 2016), and adaptive cognitive and affective outcomes (Sebire et al., 2009).

Despite participants being primarily motivated by intrinsic goals, there was also evidence of extrinsic goals. Specifically, two participants alluded to how the extrinsic goal of appearance influenced their participation, which could be underpinned by either autonomous (i.e., value particular body shape) or controlled regulations (i.e., feel pressure/guilt to aspire to particular body shape) (Sebire et al., 2009) . Furthermore, some participants were motivated by social affiliation reasons, which in this sample were reflective of either intrinsic or extrinsic motivation. Specifically, for some participants social affiliation was experienced as autonomous behavioural regulation because they enjoyed spending time with their friends, but for others it was controlling because they felt pressure from friends to attend the class. Although these extrinsic goals were evident in this group, it is unlikely that they were the primary or only reasons for participation in HIT, because they are not associated with continued participation (Teixeira et al., 2012). A final reason identified by participants related to beginning HIT was that they felt dissatisfied and bored with the activity 
they currently engaged in. Although this particular theme does not fit with the goal contents theory explicitly (Deci \& Ryan, 2000), other theoretical perspectives indicate that boredom through a lack of challenge would reduce the likelihood of experiencing flow, which is associated with high levels of enjoyment (Csikszentmihalyi, 1975). Therefore, it could be suggested that some individuals were initially intrinsically motivated to try HIT as an alternative mode of exercise because it may be more enjoyable (i.e., less boring) than current classes and activities.

Interestingly, participants perceived a greater number of goals for continued HIT participation than goals for beginning HIT. This range of goals may have helped support participants' continued participation in HIT. Indeed, Teixeira et al. (2012) highlighted that there is growing evidence that a motivational profile of identified and intrinsic behavioural regulations is important to start and then sustain exercise over time. That is, there may be times when participants are not intrinsically motivated to participate in the HIT class, but they identify with the activity, or value the outcome which results in sustained motivation.

\section{Creating a Needs Supportive Environment}

According to SDT, intrinsic motivation for an activity cannot be sustained unless the environment is needs supportive (R. M. Ryan \& Deci, 2000). Social environments that are supportive of these needs can facilitate autonomous motivation (Deci \& Ryan, 2000), leading to more enduring behaviour. However, exercise-related research has not fully supported this proposition with competence showing the strongest and most consistent relationship with autonomous motivation (Wilson \& Rogers, 2008) and exercise behaviour (Teixiera et al., 2012). Nevertheless, the findings of this study provided some insight into how a HIT class can be motivating by supporting the basic needs of competence, autonomy and relatedness. Specifically, participants identified that the HIT structure, exercises, instructors and other class participants could all support these needs thus encouraging continued engagement with HIT classes.

Participants perceived that the structure specific to HIT exercises incorporating work-rest cycles with regular short breaks helped them feel competent. Specifically, knowing that there was a 
break coming and having the opportunity to recover were both important in helping participants feel that sustaining the high intensity exercise throughout the class was attainable. Related to this finding, other researchers have suggested that the intermittent nature of HIT, incorporating breaks, may positively influence participants' affective responses compared to continuous exercise (Jung et al., 2016). Although further research is required, the intermittent nature of HIT appears to be an important characteristic of this type of exercise that could influence psychological responses. Linked to the structure, participants also discussed how the variety of exercises and the opportunity to opt for a modified exercise (if needed) helped them feel competent because they always felt they would be able to do something. Both the structure and exercises of HIT contribute to creating an experience that was challenging but attainable for participants, and therefore also supported feelings of competence (Standage \& Ryan, 2012). Furthermore, having the opportunity to choose a challenging or modified exercise supported participants' autonomy, and is likely to enhance autonomous motivation and participation (Wulf, Freitas, \& Tandy, 2014).

The instructor appeared to play an important motivational role in the HIT class. Specifically, the instructor encouraged participants, provided constructive advice to correct technique and appeared to be similar to the participants, all of which can reinforce feelings of competence (Hancox, Quested, Thogersen-Ntoumani, \& Ntoumanis, 2015; Standage \& Ryan, 2012). By communicating that there were options relating to specific exercises, instructors helped to reinforce participants' feelings of autonomy and that they had choices. SDT finds that autonomy supportive communication styles can ensure choice is perceived as self-endorsed by participants which in turn has been noted to increase physical activity behaviour and positive affect (Edmunds, Ntoumanis, \& Duda, 2008). Furthermore, the participants recognised that some instructors could create a sense of belongingness to the group through using inclusive language (Hancox et al., 2015), and demonstrating that they cared about participants, both behaviours that support feelings of relatedness (Standage \& Ryan, 2012). Finally, the other class participants appeared to be important in supporting needs. For some, attending class with friends was a particularly important relatedness 
support. Indeed, Standage and Ryan (2012) highlighted that having an 'exercise buddy' can be helpful to provide relational support. For some participants, the group exercise environment was a sufficient relatedness support, without necessitating interaction with other people in the class. Participants felt part of a cohesive group while in a HIT class which has been noted as an important relatedness support (Deci \& Ryan, 2000). In addition to feeling related to members of the group, working as part of a group also helped encourage individuals to feel competent that they could keep going. As much of the HIT research to date has been laboratory based (e.g., Jung et al., 2014), limited research has considered the social environment in which individuals may engage in HIT exercise. It is apparent from this study that the instructor and classmates can be supportive, therefore creating an enhanced motivational environment.

This is the first study to use a theoretical lens to qualitatively investigate why individuals participate in HIT exercise classes. For the participants in this sample there were a number of reasons for participating in HIT, which were mainly underpinned by intrinsic and identified behavioural regulations. These findings show that some people can be motivated to engage in HIT for adaptive reasons, suggesting that HIT may be appealing to some groups. As the participants in this sample were physically active, then the findings may not generalise to low active participants who are the target of public health campaigns. The sample included only one male participant, therefore future work should aim to engage a wider range of participants, in order to assess if gender influences motivation for HIT. Future research could aim to undertake a longitudinal qualitative study with low active participants who are new to HIT in order to explore the motivational processes in this group as they start, and continue or dropout from the classes. This paper focused on the needs supportive elements of the HIT exercise class, therefore future work could investigate needs thwarting characteristics of exercises classes. Additionally, future research would be valuable to identify individual characteristics that may influence motivation to participate in HIT such as physical activity history, or tolerance and preferences for exercise (Ekkekakis, Hall, \& Petruzzello, 2005). 
Nevertheless, the findings of this study provide useful insight into how HIT classes and interventions can be structured to address psychological needs and facilitate the development of autonomous motivation. Specifically, the classes should be structured to incorporate a variety of intermittent exercises with options and progression. Further, the instructors of HIT can help create a positive social environment by using positive feedback that is encouraging and autonomy supportive, and statements like "we can do this together" to create a sense of relatedness amongst the group. Similar to previous research focused on cycle-based HIT classes (Ntoumanis, ThogersenNtoumani, Quested, \& Hancox, 2016), future intervention research could evaluate the effectiveness of incorporating these need supportive characteristics into HIT classes.

\section{Conclusion}

To our knowledge, this is the first theory-based and qualitative study to examine the motivational processes underpinning participation in HIT group exercise classes. Although there is debate surrounding the feasibility of HIT as a public health solution, this research suggests that some individuals are adaptively motivated to participate in HIT, and supports the proposal that HIT could be part of a 'smorgasbord' of options to be physically active (Biddle \& Batterham, 2015, p.2). Whilst it is acknowledged that the sample in this study are not representative of an inactive population, the findings also contribute to this debate by making suggestions as to how the motivational climate of a HIT session can be tailored to support participants to have a positive experience, which would enhance motivation.

\section{Funding Source}

No funding source was used for this research. 


\section{References}

Biddle, S. J. H., \& Batterham, A. M. (2015). High-intensity interval exercise training for public health: a big HIT or shall we HIT it on the head? Int J Behav Nutr Phys Act, 12(95), 1-8. doi:10.1186/s12966-015-0254-9

Borg, G. (1970). Perceived exertion as an indicator of somatic stress. Scand J Rehabil Med, 2(2), 9298.

Braun, V., \& Clarke, V. (2006). Using thematic analysis in psychology. Qualitative Research in Psychology, 3, 77-101.

Csikszentmihalyi, M. (1975). Beyond boredom and anxiety. San Francisco, CA: Jossey-Bass.

Deci, E. L., \& Ryan, R. M. (2000). The "what" and "why" of goal pursuits: Human needs and the selfdetermination of behavior. Psychological Inquiry, 11(4), 227-268. doi:Doi 10.1207/S15327965pli1104_01

Department of Health, P. A., Health Improvement and Protection,. (2011). Start active, stay active: A report on physical health for health from the four home countries' Chief Medical Officers. Retrieved from London

Edmunds, J., Ntoumanis, N., \& Duda, J. L. (2008). Testing a self- determination theory- based teaching style intervention in the exercise domain. European Journal of Social Psychology, 38(2), 375-388. doi:10.1002/ejsp.463

Ekkekakis, P., Hall, E. E., \& Petruzzello, S. J. (2005). Some like it vigorous: Measuring individual differences in the preference for and tolerance of exercise intensity. Journal of Sport \& Exercise Psychology, 27(3), 350-374.

Gibala, M. J., Little, J. P., Macdonald, M. J., \& Hawley, J. A. (2012). Physiological adaptations to lowvolume, high-intensity interval training in health and disease. J Physiol, 590(5), 1077-1084. doi:10.1113/jphysiol.2011.224725

Hancox, J. E., Quested, E., Thogersen-Ntoumani, C., \& Ntoumanis, N. (2015). An intervention to train group exercise class instructors to adopt a motivationally adaptive communication style: a quasi-experiemental study protocol. Health Psychology Behaviour Medicine, 3, 190-203.

Hardcastle, S. J., Ray, H., Beale, L., \& Hagger, M. S. (2014). Why sprint interval training is inappropriate for a largely sedentary population. Front Psychol, 5(1505), 1-3. doi:10.3389/fpsyg.2014.01505

Ingledew, D. K., \& Markland, D. (2008). The role of motives in exercise participation. Psychology \& Health, 23, 807-828.

Jung, M. E., Bourne, J. E., \& Little, J. P. (2014). Where Does HIT Fit? An Examination of the Affective Response to High-Intensity Intervals in Comparison to Continuous Moderate- and Continuous Vigorous-Intensity Exercise in the Exercise Intensity-Affect Continuum. Plos One, 9(12), e114541. doi:10.1371/journal.pone.0114541

Jung, M. E., Little, J. P., \& Batterham, A. M. (2016). Commentary Why sprint interval training is inappropriate for a largely sedentary population. Front Psychol, 6(1999), 1-3. doi:10.3389/fpsyg.2015.01999

Kessler, H. S., Sisson, S. B., \& Short, K. R. (2012). The Potential for High-Intensity Interval Training to Reduce Cardiometabolic Disease Risk. Sports Medicine, 42(6), 489-509.

Kohl, H. W., Craig, C. L., Lambert, E. V., Inoue, S., Alkandari, J. R., Leetongin, G., . . Workin, L. P. A. S. (2012). The pandemic of physical inactivity: global action for public health. Lancet, 380(9838), 294-305. doi:10.1016/S0140-6736(12)60898-8

Lee, I. M., Shiroma, E. J., Lobelo, F., Puska, P., Blair, S. N., Katzmarzyk, P. T., \& Workin, L. P. A. S. (2012). Effect of physical inactivity on major non-communicable diseases worldwide: an analysis of burden of disease and life expectancy. Lancet, 380(9838), 219-229.

doi:10.1016/S0140-6736(12)61031-9 
Markland, D., \& Ingledew, D. K. (1997). The measurement of exercise motives: Factorial validity and invariance across gender of a revised exercise motivations inventory. British Journal of Health Psychology, 2, 361-376.

Milanovic, Z., Sporis, G., \& Weston, M. (2015). Effectiveness of High-Intensity Interval Training (HIT) and Continuous Endurance Training for VO2max Improvements: A Systematic Review and Meta-Analysis of Controlled Trials. Sports Medicine, 45(10), 1469-1481. doi:10.1007/s40279015-0365-0

Ntoumanis, N., Thogersen-Ntoumani, C., Quested, E., \& Hancox, J. E. (2016). The effects of training group exercise class instructors to adopt a motivationally adaptive communication style. Scandinavian Journal of Medicine \& Science in Sports.

Rouse, P. C., Ntoumanis, N., Duda, J. L., Jolly, K., \& Williams, G. C. (2011). In the beginning: Role of autonomy support on the motivation, mental health and intentions of participants entering an exercise referral scheme. Psychology \& Health, 26(6), 729-749. doi:10.1080/08870446.2010.492454

Ryan, R. M., \& Deci, E. L. (2017). Self-Determination Theory: Basic Psychological Needs in Motivation, Development, and Wellness. New York: The Guilford Press. .

Ryan, R. M., \& Deci, E. L. (2000). Self-determination theory and the facilitation of intrinsic motivation, social development, and well-being. Am Psychol, 55(1), 68-78.

Sebire, S. J., Standage, M., \& Vansteenkiste, M. (2009). Examining intrinsic versus extrinsic exercise goals: cognitive, affective, and behavioral outcomes. J Sport Exerc Psychol, 31(2), 189-210.

Standage, M., \& Ryan, R. M. (2012). Self-determination theory and exercise motivation: Facilitating self-regulatory processes to support and maintain health and well-being. In G. C. Roberts \& D. C. Treasure (Eds.), Advances in Motivation in Sport and Exercise. Champaign, IL: Human Kinetics.

Stork, M. J., Banfield, L. E., Gibala, M. J., \& Martin Ginis, K. A. (2017). A scoping review of the psychological responses to interval exercise: is interval exercise a viable alternative to traditional exercise? Health Psychology Review, 1-21. doi:10.1080/17437199.2017.1326011

Teixeira, P. J., Carraca, E. V., Markland, D., Silva, M. N., \& Ryan, R. M. (2012). Exercise, physical activity, and self-determination theory: A systematic review. International Journal of Behavioral Nutrition and Physical Activity, 9. doi:Artn 7810.1186/1479-5868-9-78

Thogersen-Ntoumani, C., Shepherd, S. O., Ntoumanis, N., Wagenmakers, A. J. M., \& Shaw, C. S. (2016). Intrinsic Motivation in Two Exercise Interventions: Associations With Fitness and Body Composition. Health Psychology, 35(2), 195-198. doi:10.1037/hea0000260

Thompson, W. R. (2014). WORLDWIDE SURVEY OF FITNESS TRENDS FOR 2015 What's Driving the Market. Acsms Health \& Fitness Journal, 18(6), 8-17. doi:10.1249/Fit.0000000000000073

Thompson, W. R. (2015). WORLDWIDE SURVEY OF FITNESS TRENDS FOR 2016 10th Anniversary Edition. Acsms Health \& Fitness Journal, 19(6), 9-18.

Thompson, W. R. (2016). Worldwide Survey of Fitness Trends for 2017. Acsms Health \& Fitness Journal, 20(6), 8-17. doi:10.1249/Fit.0000000000000252

Tong, A., Sainsbury, P., \& Craig, J. (2007). Consolidated criteria for reporting qualitative research (COREQ): a 32-item checklist for interviews and focus groups. Int J Qual Health Care, 19(6), 349-357. doi:10.1093/intqhc/mzm042

Vierling, K. K., Standage, M., \& Treasure, D. C. (2007). Predicting attitudes and physical activity in an "at-risk" minority youth sample: A test of self-determination, theory. Psychology of Sport and Exercise, 8(5), 795-817. doi:10.1016/j.psychsport.2006.12.006

Wulf, G., Freitas, H. E., \& Tandy, R. D. (2014). Choosing to exercise more: Small choices increase exercise engagement. Psychology of Sport \& Exercise, 15(3), 268-271.

doi:10.1016/j.psychsport.2014.01.007 


\section{Tables}

Table 1: Completed consolidated criteria for reporting qualitative studies (COREQ) checklist

\begin{tabular}{|c|c|c|}
\hline No. Item & Guide questions/description & Reported on Page \# \\
\hline \multicolumn{3}{|l|}{$\begin{array}{l}\text { Domain 1: Research team } \\
\text { and reflexivity }\end{array}$} \\
\hline \multicolumn{3}{|l|}{ Personal Characteristics } \\
\hline 1. Inter viewer/facilitator & $\begin{array}{l}\text { Which author/s conducted the inter view or } \\
\text { focus group? }\end{array}$ & $\begin{array}{l}\text { Method> } \\
\text { Participants and } \\
\text { recruitment> page } 7\end{array}$ \\
\hline 2. Credentials & $\begin{array}{l}\text { What were the researcher's credentials? E.g. } \\
\text { PhD, MD }\end{array}$ & $\begin{array}{l}\text { Method }> \\
\text { Participants and } \\
\text { recruitment> page } 7\end{array}$ \\
\hline 3. Occupation & $\begin{array}{l}\text { What was their occupation at the time of the } \\
\text { study? }\end{array}$ & $\begin{array}{l}\text { Method> } \\
\text { Participants and } \\
\text { recruitment> page } 7\end{array}$ \\
\hline 4. Gender & Was the researcher male or female? & $\begin{array}{l}\text { Method> } \\
\text { Participants and } \\
\text { recruitment> page } 7\end{array}$ \\
\hline 5. Experience and training & $\begin{array}{l}\text { What experience or training did the researcher } \\
\text { have? }\end{array}$ & $\begin{array}{l}\text { Method> } \\
\text { Participants and } \\
\text { recruitment> page } 7\end{array}$ \\
\hline \multicolumn{3}{|l|}{ Relationship with participants } \\
\hline 6. Relationship established & $\begin{array}{l}\text { Was a relationship established prior to study } \\
\text { commencement? }\end{array}$ & $\begin{array}{l}\text { Method }> \\
\text { Procedure }>\text { page } 7\end{array}$ \\
\hline $\begin{array}{l}\text { 7. Participant knowledge of } \\
\text { the interviewer }\end{array}$ & $\begin{array}{l}\text { What did the participants know about the } \\
\text { researcher? e.g. personal goals, reasons for } \\
\text { doing the research }\end{array}$ & $\begin{array}{l}\text { Method }> \\
\text { Procedure }>\text { page } 7\end{array}$ \\
\hline 8. Interviewer characteristics & $\begin{array}{l}\text { What characteristics were reported about the } \\
\text { inter viewer/facilitator? e.g. Bias, assumptions, } \\
\text { reasons and interests in the research topic }\end{array}$ & $\begin{array}{l}\text { Method> } \\
\text { Participants and } \\
\text { recruitment> page } 7\end{array}$ \\
\hline \multicolumn{3}{|l|}{ Domain 2: study design } \\
\hline \multicolumn{3}{|l|}{ Theoretical framework } \\
\hline $\begin{array}{l}\text { 9. Methodological orientation } \\
\text { and Theory }\end{array}$ & $\begin{array}{l}\text { What methodological orientation was stated } \\
\text { to underpin the study? e.g. grounded theory, } \\
\text { discourse analysis, ethnography, } \\
\text { phenomenology, content analysis }\end{array}$ & $\begin{array}{l}\text { Introduction> Self- } \\
\text { determination } \\
\text { theory> pages } 3-6\end{array}$ \\
\hline \multicolumn{3}{|l|}{ Participant selection } \\
\hline 10. Sampling & $\begin{array}{l}\text { How were participants selected? e.g. } \\
\text { purposive, convenience, consecutive, snowball }\end{array}$ & $\begin{array}{l}\text { Method }> \\
\text { Procedure> page } 6\end{array}$ \\
\hline 11. Method of approach & $\begin{array}{l}\text { How were participants approached? e.g. face- } \\
\text { to-face, telephone, mail, email }\end{array}$ & $\begin{array}{l}\text { Method> } \\
\text { Participants and }\end{array}$ \\
\hline
\end{tabular}


Motivation for high-intensity interval training

\begin{tabular}{|c|c|c|}
\hline & & $\begin{array}{l}\text { recruitment> pages } \\
7-8\end{array}$ \\
\hline 12. Sample size & How many participants were in the study? & $\begin{array}{l}\text { Method }> \\
\text { Procedure> pages 7- } \\
8\end{array}$ \\
\hline 13. Non-participation & $\begin{array}{l}\text { How many people refused to participate or } \\
\text { dropped out? Reasons? }\end{array}$ & $\begin{array}{l}\text { Method }> \\
\text { Procedure > page } 7\end{array}$ \\
\hline \multicolumn{3}{|l|}{ Setting } \\
\hline 14. Setting of data collection & $\begin{array}{l}\text { Where was the data collected? e.g. home, } \\
\text { clinic, workplace }\end{array}$ & $\begin{array}{l}\text { Method }> \\
\text { Procedure> page } 8\end{array}$ \\
\hline $\begin{array}{l}\text { 15. Presence of non- } \\
\text { participants }\end{array}$ & $\begin{array}{l}\text { Was anyone else present besides the } \\
\text { participants and researchers? }\end{array}$ & $\mathrm{n} / \mathrm{a}$ \\
\hline 16. Description of sample & $\begin{array}{l}\text { What are the important characteristics of the } \\
\text { sample? e.g. demographic data, date }\end{array}$ & $\begin{array}{l}\text { Method }> \\
\text { Procedure> page } 8\end{array}$ \\
\hline \multicolumn{3}{|l|}{ Data collection } \\
\hline 17. Interview guide & $\begin{array}{l}\text { Were questions, prompts, guides provided by } \\
\text { the authors? Was it pilot tested? }\end{array}$ & $\begin{array}{l}\text { Method> } \\
\text { Instrument> page } 7\end{array}$ \\
\hline 18. Repeat interviews & $\begin{array}{l}\text { Were repeat inter views carried out? If yes, } \\
\text { how many? }\end{array}$ & $\mathrm{n} / \mathrm{a}$ \\
\hline 19. Audio/visual recording & $\begin{array}{l}\text { Did the research use audio or visual recording } \\
\text { to collect the data? }\end{array}$ & $\begin{array}{l}\text { Method }> \\
\text { Procedure }>\text { page } 8\end{array}$ \\
\hline 20. Field notes & $\begin{array}{l}\text { Were field notes made during and/or after the } \\
\text { inter view or focus group? }\end{array}$ & $n / a$ \\
\hline 21. Duration & $\begin{array}{l}\text { What was the duration of the inter views or } \\
\text { focus group? }\end{array}$ & $\begin{array}{l}\text { Method }> \\
\text { Procedure> page } 8\end{array}$ \\
\hline 22. Data saturation & Was data saturation discussed? & $\begin{array}{l}\text { Method }> \\
\text { Procedure> page } 8\end{array}$ \\
\hline 23. Transcripts returned & $\begin{array}{l}\text { Were transcripts returned to participants for } \\
\text { comment and/or correction? }\end{array}$ & $\mathrm{n} / \mathrm{a}$ \\
\hline \multicolumn{3}{|l|}{$\begin{array}{l}\text { Domain 3: analysis and } \\
\text { findings }\end{array}$} \\
\hline \multicolumn{3}{|l|}{ Data analysis } \\
\hline 24. Number of data coders & How many data coders coded the data? & $\begin{array}{l}\text { Method }>\text { Analysis }> \\
\text { page } 8\end{array}$ \\
\hline $\begin{array}{l}\text { 25. Description of the coding } \\
\text { tree }\end{array}$ & $\begin{array}{l}\text { Did authors provide a description of the coding } \\
\text { tree? }\end{array}$ & Figures 1,2 and 3 \\
\hline 26. Derivation of themes & $\begin{array}{l}\text { Were themes identified in advance or derived } \\
\text { from the data? }\end{array}$ & $\begin{array}{l}\text { Method }>\text { Analysis }> \\
\text { page } 8\end{array}$ \\
\hline 27. Software & $\begin{array}{l}\text { What software, if applicable, was used to } \\
\text { manage the data? }\end{array}$ & $\begin{array}{l}\text { Method>Analysis> } \\
\text { page } 8\end{array}$ \\
\hline 28. Participant checking & $\begin{array}{l}\text { Did participants provide feedback on the } \\
\text { findings? }\end{array}$ & $\mathrm{n} / \mathrm{a}$ \\
\hline Reporting & & \\
\hline
\end{tabular}




\begin{tabular}{|l|l|l|}
\hline 29. Quotations presented & $\begin{array}{l}\text { Were participant quotations presented to } \\
\text { illustrate the themes/findings? Was each } \\
\text { quotation identified? e.g. participant number }\end{array}$ & $\begin{array}{l}\text { Yes. Results pages 9- } \\
15\end{array}$ \\
\hline $\begin{array}{l}\text { 30. Data and findings } \\
\text { consistent }\end{array}$ & $\begin{array}{l}\text { Was there consistency between the data } \\
\text { presented and the findings? }\end{array}$ & Results pages 9-15 \\
\hline 31. Clarity of major themes & $\begin{array}{l}\text { Were major themes clearly presented in the } \\
\text { findings? }\end{array}$ & $\begin{array}{l}\text { Results pages 9-15. } \\
\text { Figures 1,2 and 3 }\end{array}$ \\
\hline 32. Clarity of minor themes & $\begin{array}{l}\text { Is there a description of diverse cases or } \\
\text { discussion of minor themes? }\end{array}$ & $\begin{array}{l}\text { Results pages 9-15. } \\
\text { Particularly page 10 } \\
\text { and page 12. For } \\
\text { themes "dissatisfied } \\
\text { with current } \\
\text { routine" and } \\
\text { appearance related } \\
\text { motives. }\end{array}$ \\
\hline
\end{tabular}




\section{Figures}

Figure 1: Goal contents and behavioural regulations for starting HIT group exercise classes

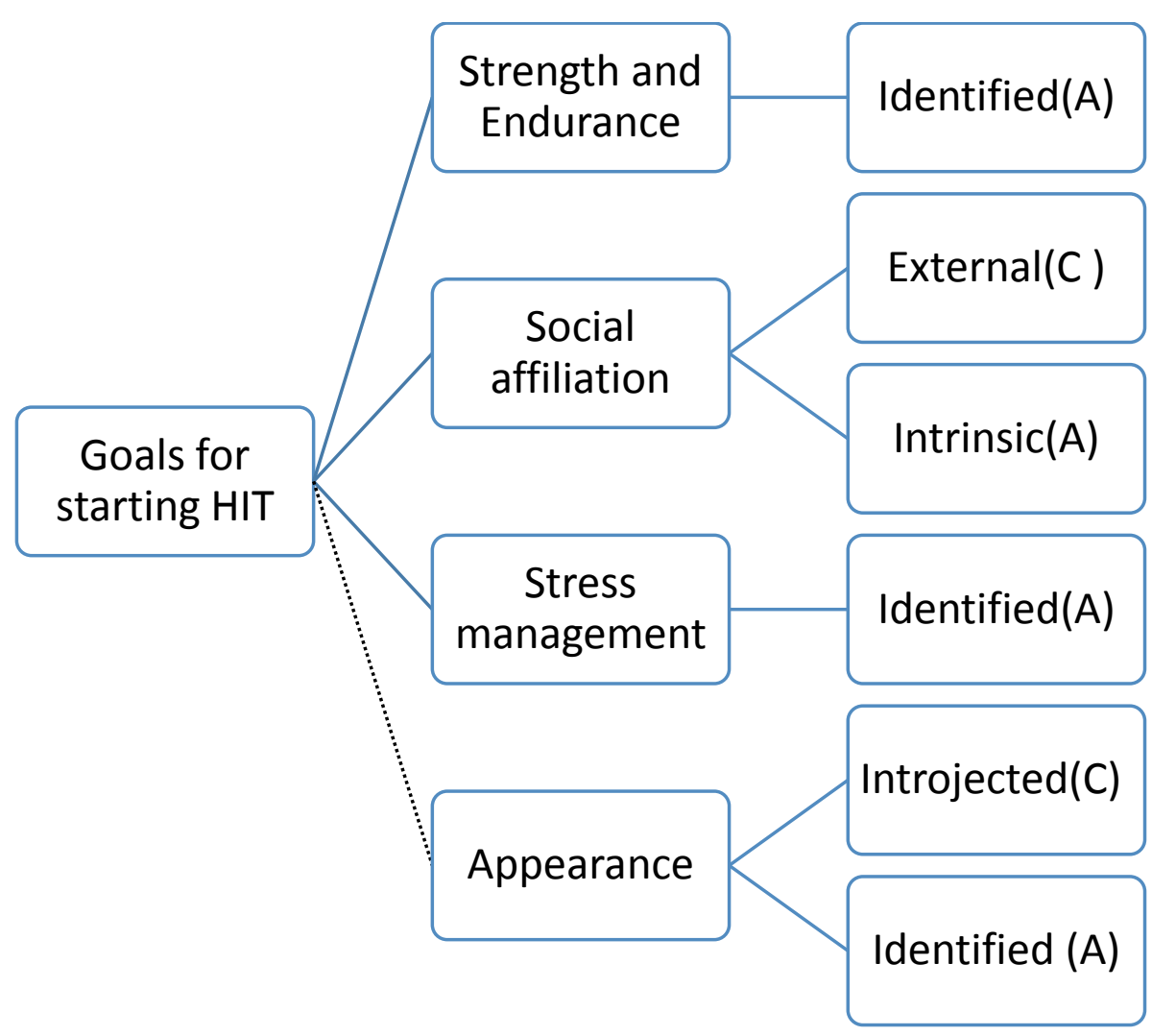

Key:

$=$ Not explicitly discussed as a

motive for starting HIT 
Figure 2: Goal contents for continuing HIT group exercise classes

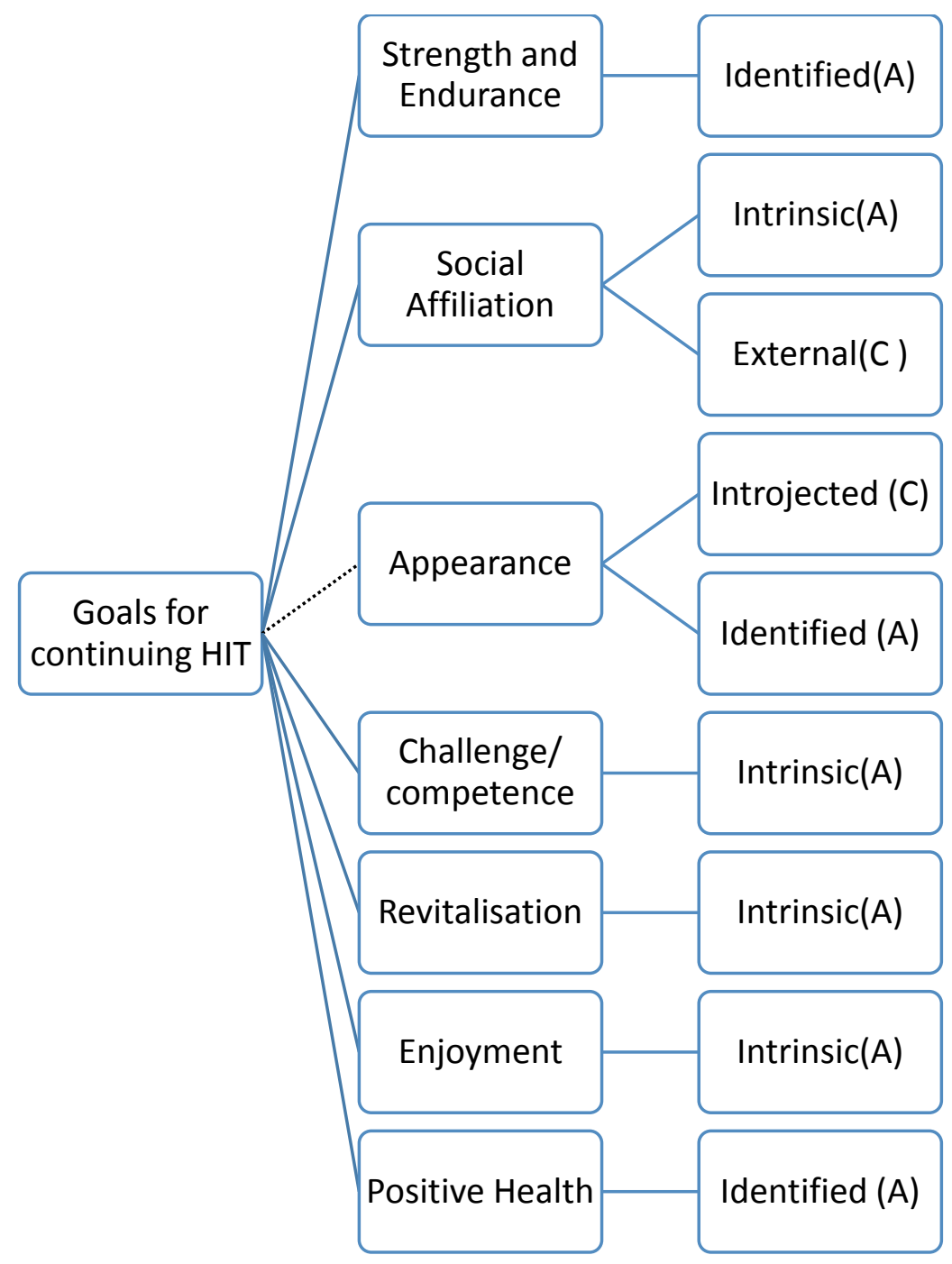

Key:

$=$ Not explicitly discussed as a

motive for starting HIT 
Figure 3: Elements of a HIT class that helped create a needs supportive environment

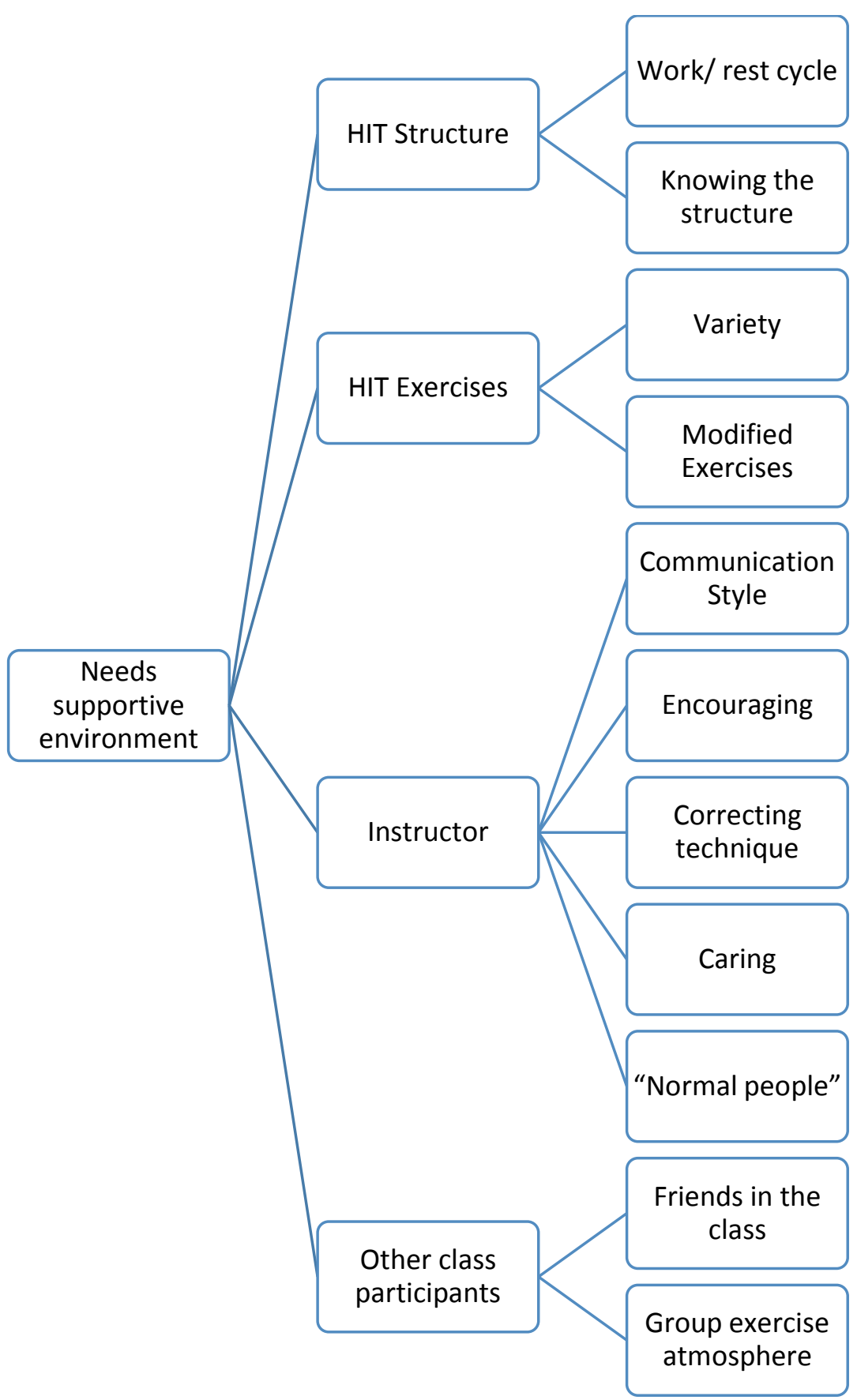

